\title{
Modelo sistémico para la conformación de un cluster turístico regional de naturaleza sustentable
}

\section{Systemic model for the formation of a regional touristic cluster of sustainable nature}

\author{
Oscar Montaño-Arango \\ José Ramón Corona-Armenta \\ Jaime Garnica-GonzÁlez \\ Heriberto Niccolas-Morales \\ Pablo Martínez-Castelán \\ Antonio Oswaldo Ortega-Reyes*
}

\begin{abstract}
A systemic model that displays and analyzes the different levels and elements involved in the tourism of sustainable nature as a trigger for regional development is presented. The results are product of an exploratory diagnosis that groups the indicators of touristic potential that support the model. Actors involved, as well as their integration role for the tourist sector were detected, in which through the conceptualization, understanding and analysis of the system, alternatives to regional tourism development were generated with emphasis on economic, social, cultural and environmental aspects.
\end{abstract}

Keywords: systemic model, sustainability, cluster, tourism, regional development.

\section{Resumen}

Se presenta un modelo sistémico que visualiza y analiza los diferentes niveles y elementos que intervienen en el turismo de naturaleza sustentable como detonante del desarrollo regional, a través de un diagnóstico exploratorio, las vertientes que lo sustentan y la identificación de indicadores de potencialidad turística. Se detectan los actores que deben intervenir; así como la integración que debe tener el sector turístico, donde a través de la conceptualización, entendimiento y análisis del sistema, se generan alternativas para el desarrollo turístico regional con énfasis en los beneficios económicos, sociales, culturales y ambientales.

Palabras clave: modelo sistémico, sustentabilidad, cluster, turismo, desarrollo regional.

*Universidad Autónoma del Estado de Hidalgo, México. Correos-e: oscarma11@hotmail.com, jrcorarm@yahoo.com, jgarnicag@gmail.com, hnicolas@uaeh.edu.mx, p_mtz_castelan2@yahoo.com. mx, oswwaldoo@yahoo.com.mx. 


\section{Introducción}

Ante las crisis mundiales y las propias del país, es imperante la planeación estratégica aplicada con un enfoque sistémico para conseguir un mejor futuro en cuestiones económicas y sociales que respeten el medio ambiente (Tarlombani, 2005). Los recursos naturales pueden potencializar los ingresos y sustentabilidad de una región, apoyados en el turismo como uno de los agentes más efectivos de integración de economías menos desarrolladas, conforme a los modelos mundiales establecidos (Pérez, 2004), donde el turismo se enfrenta a los problemas que plantean dos paradigmas no coincidentes: la globalización y la sustentabilidad (Fonseca, 2009; Cevallos, 1998).

Se puede visualizar y estructurar el potencial de turismo sustentable de naturaleza de una región (es el caso del municipio de Acaxochitlán, Hidalgo), como una actividad económica que contribuya en el desarrollo de regiones marginadas y con pocas oportunidades de crecimiento, con una base de desarrollo equitativo, seguido de la adecuación y creación de infraestructura que apoye la economía y el uso eficiente de los recursos naturales para la producción de bienes y servicios (Urquidi, 2002). Se considera que en las regiones de México se puede impulsar el desarrollo al mejorar su equidad, eficiencia y sustentabilidad, al propiciar la reflexión acerca de cuáles pueden ser las aplicaciones del concepto de entropía regional (Miguel et al., 2008). Al respecto, Rodríguez (2007) menciona que no hay que desestimar la problemática e impactos que genera la industria del turismo en los aspectos políticos, sociales, económicos, étnicos, culturales y ambientales. Acerca de este último punto, Salinas y Osorio señalan que "el sector turístico es particularmente sensible en sus relaciones, ya que por un lado consume recursos naturales y por el otro necesita un entorno natural atractivo para su desarrollo" (2006: 202).

Para abordar lo anterior se definió un planteamiento metodológico de tipo exploratorio, no experimental de diseńo transeccional (Hernández et al., 2006), y desde la perspectiva de la investigación de mercados, que se enfoca en brindar información y ayuda para comprender el problema a resolver (Malhotra, 2008) basado en la integridad sistémica como marco de referencia, que contempla diversos niveles analíticos para el desarrollo de una localidad (Esser et al., 1996). Asimismo se consideran las tres categorías de la metodología para un ecoturismo TAP (turismo ambientalmente planificado): la utilización de un enfoque interdisciplinario, la planeación participativa y la sustentabilidad (Chávez, 2007); así como los lineamentos para la integración de agrupamientos turísticos de la Secretaría de Turismo (Sectur, 2007) y con base en el objetivo indicado por la Agenda 21 para el turismo mexicano, proponer estrategias orien- 
tadas al fortalecimiento de los destinos turísticos, con trabajo que coadyuve al desarrollo sustentable de las actividades turísticas, para consolidar el bienestar del ser humano con la premisa de conservar el medio ambiente y la cultura (Sectur, 2008).

Silva (2005) señala que la agrupación que tenga el turismo como actividad nuclear, cuyo foco es el destino turístico entendido como un microcluster, y que presente como característica una clara delimitación de amplitud geográfica de su entorno espacial, del ámbito territorial que abarca la propia agrupación, del segmento turístico principal y de los subsegmentos relacionados, puede corresponder a la configuración de un cluster de turismo donde se reúnan las condiciones para promover y modelar estrategias de crecimiento y desarrollo para las microrregiones o zonas turísticas. Por tanto, la finalidad es que el turismo sea sustentable y competitivo y debe dejar de funcionar bajo el esquema de conglomerados productivos y operar como un grupo estratégico y alineado (Peres, 2006), funcionamiento que se plantea mediante el esquema de microclusters articulados, basados en el uso y aprovechamiento de recursos naturales capaces de contribuir al desarrollo sustentable de la región.

Actualmente el turista ya no está satisfecho con tener una experiencia pasiva, busca la aventura, convivir con la naturaleza, el ambiente del lugar y entender la cultura (Cooper et al., 1996). Goeldner y Brent (2002) mencionan que tampoco se busca el mejor transporte o los mejores hoteles, sino que se brinde un sabor local, manteniendo las formas de vida tradicional y que se proyecte una imagen de los beneficios que se le pueden dar al turista.

La investigación se estructura en los siguientes apartados: 1) Marco contextual y conceptual, 2) Modelo sistémico, 3) Diagnóstico exploratorio del potencial turístico; 4) Análisis del diagnóstico por nivel; 5) Identificación de proyectos; y 6) Conclusiones.

Cabe hacer mención que este estudio se desarrolló con el apoyo de los fondos mixtos Conacyt-Gobierno del Estado de Hidalgo, entre los años 2008 y 2009 , donde los lineamientos se encaminan a detonar el desarrollo económico-social de la región a través de propuestas sustentables.

\section{Marco contextual y conceptual}

\subsection{Marco contextual}

El gobierno del estado de Hidalgo (2005), en su Plan de Desarrollo 20052011, punto 1.10 Turismo, planteó desarrollar este sector y consolidarlo en el corto plazo, orientado a ofrecer al viajero diversas alternativas en los tipos de turismo alternativo, negocios, cultural y familiar, mediante la promoción de un desarrollo sustentable y con respeto al entorno ecológico. Por ello, a través 
de apoyos federales y estatales, se convocó a los municipios a plantear sus necesidades y poder asignar recursos para realizar los estudios correspondientes, con la prioridad para aquellos que tuvieran el más bajo índice de desarrollo humano (IDH), ${ }^{1}$ donde el municipio de Acaxochitlán se ubicó en la posición 75 de los 84 municipios que conforman el estado de Hidalgo, con un IDH de 0.6771 (PNUD, 2008), por lo que el gobierno municipal solicitó apoyo para contar con un plan que permitiera detonar su crecimiento económico y social, a través de proyectos pertinentes y viables, que permitan elevar los diferentes indicadores económicos y de desarrollo humano.

\subsection{Marco conceptual}

El estudio parte del concepto creado por Porter que define un cluster como una "concentración geográfica y sectorial de empresas e instituciones que en su interacción generan capacidad de innovación y conocimiento especializado" (1990: 253), lo cual se complementa a través de la identificación de las cinco fuerzas de la estructura de la industria, conocidas como el Modelo Diamante de Porter (2002, 2008), donde se destaca que en los mercados de bienes y servicios en general, la construcción de ventajas competitivas se apoya especialmente en innovaciones que posibilitan la diferenciación como estrategia para conquistar el mercado del turismo y donde el marketing se considera una estrategia (Boullón, 2003).

Un cluster turístico sustentable de naturaleza surge de la interacción entre empresas e instituciones que deberán posibilitar la innovación para optimizar el uso de los recursos naturales de una manera sustentable (Cunha y Aricó, 2001) y tomar en cuenta que un producto turístico es un bien social cuando va orientado a satisfacer necesidades sociales, como la protección al turista, al medio ambiente, o los bienes instrumentales como la distribución o comercialización del producto/servicio (Ramírez, 2006). La misión de la interacción de los agentes turísticos es asegurar la sustentabilidad de la explotación de aquello que inicialmente era sólo una condición natural; es decir, se debe buscar como uno de los principales factores de atracción de la región y ser conocida por la forma en que se cuida el medio ambiente. Para lo cual es importante tomar en cuenta que cualquier proceso o actividad económica comienza con la extracción/captura/deterioro de los recursos naturales y finaliza con la emisión, el vertido o el depósito de residuos en el medio ambiente (Labandeira et al., 2007).

En lo que respecta al concepto de turismo sustentable de naturaleza, de acuerdo con la definición propuesta por un grupo de trabajo interminis-

\footnotetext{
${ }^{1}$ El IDH es la medición que utiliza el Programa de las Naciones Unidas para el Desarrollo (PNUD) para elaborar sus documentos de análisis mundial, donde selecciona tres dimensiones de medición: longevidad, conocimientos y acceso a recursos.
} 
terial integrado por los ministros de Industria, de Comercio y de Turismo y el Ministerio de Medio Ambiente, de los Recursos Hídricos y de la Amazonia Legal, retomado por Cunha, se entiende como un "segmento de actividad turística que utiliza, de manera sustentable, el patrimonio natural y cultural, incentiva su conservación y busca la formación de una conciencia ambientalista a través de la interpretación del ambiente, promoviendo el bienestar de las poblaciones involucradas" (2001: 9).

Van Broeck (2005) menciona que, no obstante, en la práctica el turismo sustentable se enfoca principalmente a los asuntos ambiental, sociocultural y económico, la United Nations Environmental Programme (UNEP) apunta a un uso óptimo de estos recursos, una minimización de daños y una maximización de los beneficios para la conservación y para las comunidades locales.

Por su parte, el concepto de competitividad sistémica busca respuestas en sus subsistemas y el medio, de forma que permita a las organizaciones construir una competitividad dinámica y duradera de su entorno con la participación interactiva de múltiples actores (Abreu, 2009; López, 2006). Para ello, consideran que se debe dar prioridad a la innovación como factor central de desarrollo y crecimiento, donde la organización debe ser capaz de aprovechar los procesos de aprendizaje para crear conocimiento y desarrollar toda su cadena productiva, mediante la coordinación de áreas, procesos y redes de colaboración, en un contexto de identificación con la región. Para este caso, la teoría del turismo distingue en la actividad múltiples dimensiones que hacen que se aborde de manera sistémica, debido a que genera efectos ambientales, sociales, políticos y económicos (Varisco, 2004). Por su parte, Vergara y Arrais (2005) mencionan que el turismo se concibe como un fenómeno o una actividad compleja que debe ser analizada con un enfoque sistémico. Vera (1997) señala que la aproximación sistémica aplicada al turismo es necesaria por la diversidad de los componentes que configuran, producen y determinan la dinámica turística. Beni (1998) señala el turismo como un sistema abierto que realiza intercambios con el medio que lo circunda y por extensión, que es interdependiente y nunca autosuficiente.

Por otra parte, para que la práctica del turismo sustentable de naturaleza sea exitosa es fundamental la formación de una conciencia y cultura ambiental, que constituya un interés compartido por todos los agentes involucrados (Ruiz, 2008).

Con base en lo anterior, se sustenta la propuesta de formación de un cluster de acuerdo con lo expuesto por la Sectur (2007), la cual plantea que un agrupamiento turístico está referenciado al espacio geográfico donde se concentran los atractivos, estos últimos conformados por los recursos naturales o artificiales y por las actividades susceptibles a desarrollar, enmarcadas en las premisas establecidas en un marco regulatorio. Por ello, es 
factible desarrollar el cluster siempre y cuando se tomen en consideración los desafíos y recomendaciones en los tres niveles antes descritos.

\section{Modelo sistémico}

Este modelo se basa en el análisis del estado de desarrollo del tejido productivo que sustenta la actividad turística (Montero y Parra, 2001), donde se tienen como ejes:

- La zona como destino de turismo con desarrollo sustentable.

- La zona como un sistema productivo tipo cluster.

- La zona y su área de influencia.

- Condiciones sociopolíticas para un desarrollo sustentable y sistémico que se traduzca en un sistema de gestión y regulación.

Cárdenas (2006) y Pascarella y Rubens (2010) señalan que es importante identificar agentes económicos y condiciones sociales que agreguen valor al turismo sustentable de naturaleza, así como desarrollar un sistema de gestión que asegure la sustentabilidad del aprovechamiento, sin dejar a un lado las necesidades de infraestructura en transporte, comunicación, servicios y equipamiento, que relacione todos los elementos turísticos que la integren debido a que es una motivación para el turista y la competitividad.

El modelo de turismo sustentable de naturaleza que se propone en esta investigación, se constituye por cuatro vertientes que representan las directrices principales para definir la cartera de proyectos (figura I), las cuales se toman como base para estructurar el cluster turístico, teniendo como referencia lo expuesto por Sectur, Cestur-UAm (2007) sobre expe-

Figura I

Representación de las vertientes del turismo sustentable de naturaleza

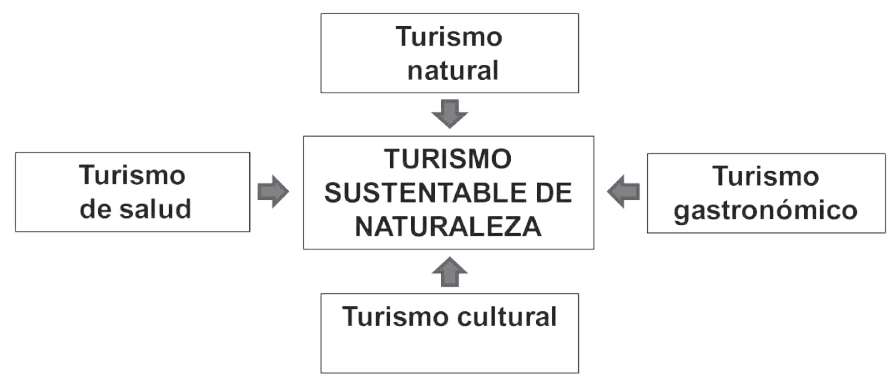

Fuente: Elaboración propia con base en Sectur, Cestur-UAM (2007). 
riencias turísticas recreativas basadas en el disfrute del capital ambiental, gastronómico e histórico-cultural.

Las cuales se pueden definir de la siguiente forma:

1. Turismo de salud. Es una de las más antiguas formas de turismo. Para lograr el restablecimiento físico, muchas personas se desplazan a otras latitudes para recibir y disfrutar las bondades curativas que ofrece la naturaleza en cuanto a clima, baños, balnearios de aguas termales, lugares de retiro y aquellos propicios para lograr un descanso que los libere de las tensiones o el estrés. Sin embargo, estas regiones pocas veces disponen de un apoyo formal por parte de las instituciones locales de salud, o bien carecen de la suficiente vigilancia y supervisión sanitarias, a fin de evitar las estafas terapéuticas (Ruiz et al., 1994).

2. Turismo gastronómico. Considera la visita a productores primarios o secundarios de alimentos, participación en festivales gastronómicos y búsqueda de restaurantes o lugares específicos donde la degustación de alimentos y toda experiencia inherente es la razón principal para viajar (Hall y Mitchel, 2002; Saramago, 2002). En este trabajo se considera que en los últimos años ha crecido este tipo de turismo y que la decisión de los visitantes se relaciona directamente con la gastronomía (Oliveira, 2007b).

3. Turismo cultural. Se basa en los recursos del patrimonio histórico y se considera que la oferta cultural de un destino es parte del atractivo y de la imagen turística de la región (Pérez, 2004). Comienza a tener éxito una vez que la comunidad participa en el proceso de su desarrollo, cuando toma conciencia de sus derechos y deberes, y logra consolidar su autoestima y su propia identidad, entonces participa de forma integral con los visitantes temporales, sin temor a que sea vulnerado su hábitat en un sentido integral (Ascanio, 2004).

4. Turismo natural. Se parte de que la naturaleza y el medio ambiente son un elemento de las políticas turísticas, donde existen espacios protegidos, recreativos y para practicar deporte (Pérez, 2004), donde es necesario contabilizar los atractivos, caracterizarlos y generar leyes, lo cual es una forma de aproximarse al espacio natural (Andrés y Encabo, 2008). Esta aproximación permite jerarquizar los atractivos, los cuales se ligan a las necesidades del mercado y a la posibilidad de obtener mayores flujos turísticos (Otero, 1997).

Es necesario tomar en cuenta que las motivaciones turísticas y la posibilidad de mayor acceso a los nuevos destinos, así como la facilidad de obtener información, conlleva a buscar opciones donde se espera encon- 
trar paisajes diferentes y agradables, conocer la cultura y las costumbres locales, con la finalidad de ampliar conocimientos (Poggi et al., 2006).

$\mathrm{Al}$ respecto, se desarrolló la cadena del valor que se muestra en la figura II, tomando como base el modelo que desarrolla Porter (2002), la cual muestra las interrelaciones entre las actividades operativas que dan el valor sustancial al turismo y las que apoyan para su gestión y desarrollo.

La figura II se puede entender desde la perspectiva de Cobo et al. (2009), que se refiere a que el turista se puede considerar como una fuente de necesidades (desplazamiento, alojamiento, manutención, ocio, compras...) y las empresas e instituciones públicas deben responder a ellas; la mayoría de las veces a través de la cooperación como única vía para su satisfacción.

Para identificar los niveles de los elementos que se relacionan con el turismo, se creó un modelo sistémico que busca expresar los elementos que forman parte del sistema turístico, sus interrelaciones y su relación con el ambiente externo (Oliveira, 2007a), el cual conjuga los conceptos de turismo sustentable de naturaleza y cluster; donde se identifican los atractivos turísticos, el medio operativo y los principales actores; de acuer-

\section{Figura II \\ Cadena del valor del turismo}

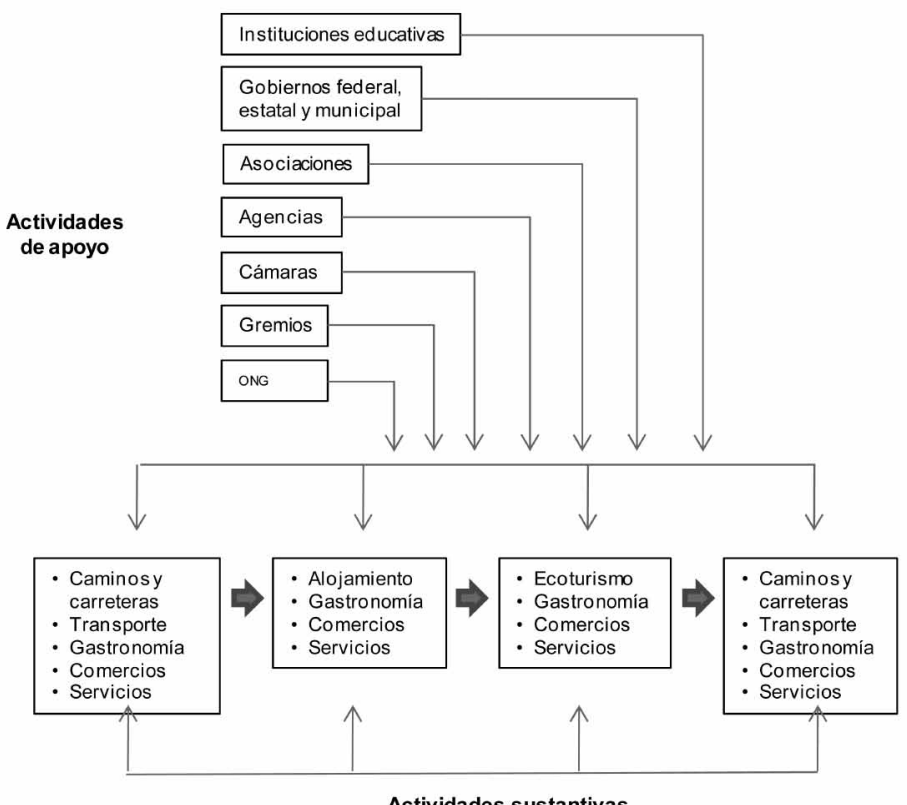

Fuente. Elaboración propia con base en Porter (2002). 
do con las correlaciones que establecen los niveles micro, meta, meso y macro que proponen Esser et al. (1996) y Meyer (2008) en sus modelos de competitividad sistémica, y con el enfoque planteado por Cunha y Aricó (2001), el cual se ilustra en la figura III.

En un primer acercamiento se identificaron dos niveles: el micro y el macro. El primero representa el conjunto de los diferentes atractivos turísticos y el trade-que representa la infraestructura y medios para poder acceder al turismo-, que al conjugarse pueden establecer ventajas competitivas (Cunha y Arico, 2001). El nivel macro es la esfera donde se condiciona la estructura económica y se definen los incentivos a través de leyes, instituciones y políticas genéricas.

Esser et al. (1996) y Meyer (2008) mencionan que la dinámica del desarrollo no sólo se basa en las funciones de los niveles micro y macro, o esfuerzos individuales y colectivos para formar un soporte ambiental para el desarrollo, el cual incluye dos nuevos niveles que se adaptan a las características del trabajo. El primero se inserta entre el nivel macro y el micro; al cual le llama nivel meso, que es donde se encuentran los actores locales encargados de direccionar las políticas específicas (regionales, de tecnología, industriales, etc.) y crear el ambiente organizacional e institucional que soporta el trade y los atractivos turísticos. El otro nivel es el

Figura III

\section{Modelo sistémico del turismo}

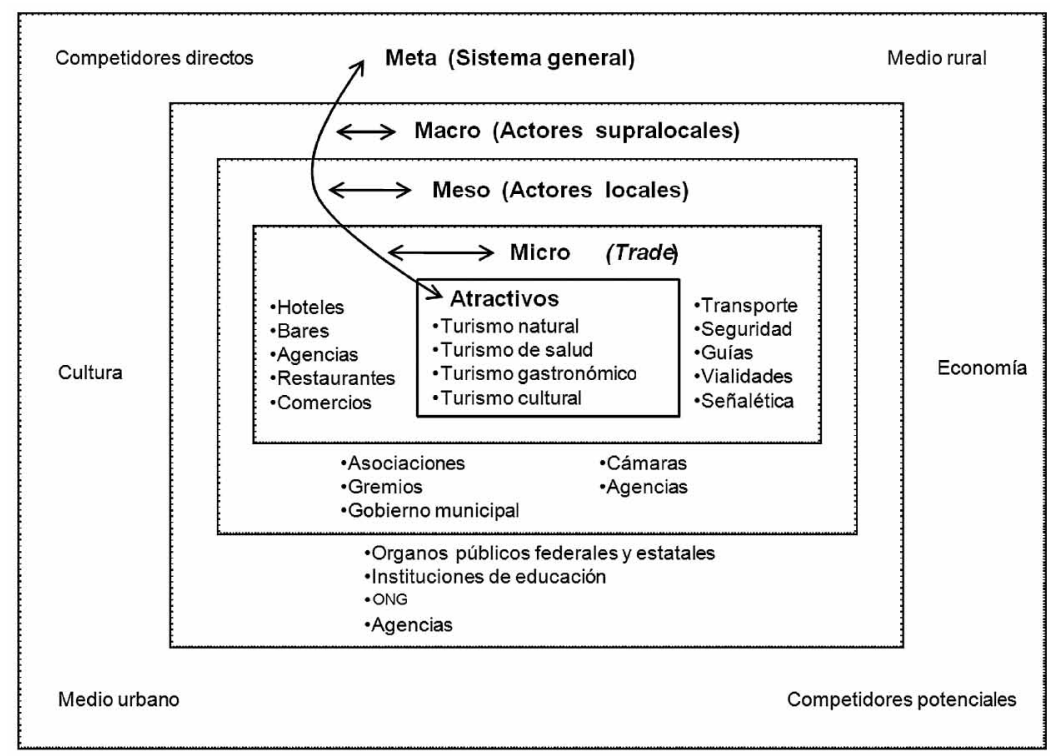

Fuente: Elaboración con base en Esser et al. (1996), Cunha y Aricó (2001) y Meyer (2008). 
meta, que direcciona las capacidades de los actores locales y supralocales, con la finalidad de crear las condiciones favorables en la región, ya que involucra a la sociedad, la economía y la competitividad. La conjugación de los elementos señalados tiene efecto en las alternativas y decisiones de selección de un destino turístico.

\section{Diagnóstico exploratorio del potencial turístico en el municipio de Acaxochitlán, Hidalgo}

La región objeto de estudio sobre el turismo sustentable de naturaleza es el municipio de Acaxochitlán, Hidalgo, donde se trabajó y recopiló información en campo durante el periodo 2008-2009.

\section{Figura IV}

Plano de localización del municipio de Acaxochitlán

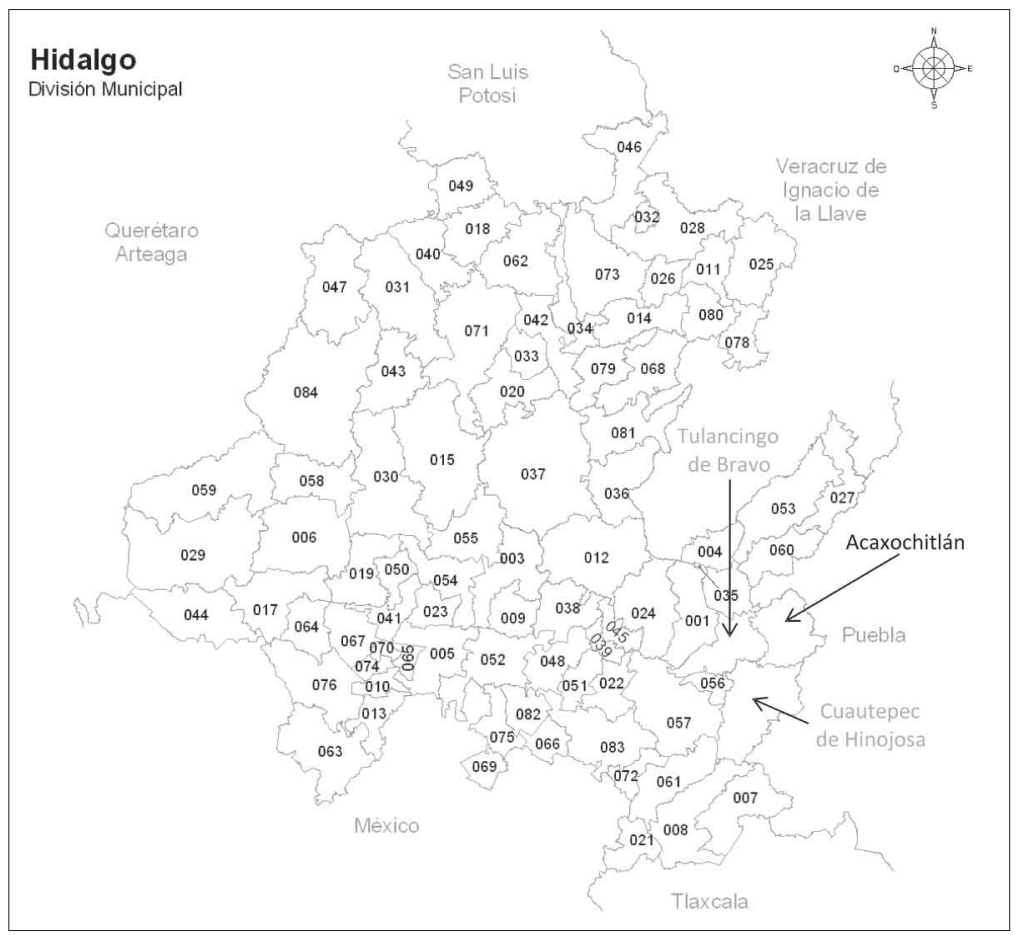

Fuente: Elaboración propia con base en el Marco Geoestadístico, INEGI, 2005b. 


\subsection{Descripción general}

Para determinar las características que se muestran en el cuadro 1 se usó como referencia la Enciclopedia de los municipios de México (2002), información del INEGI del año 2005a e información recopilada en la región.

\section{Cuadro 1 \\ Características generales de la región de Acaxochitlán}

\begin{tabular}{|c|c|}
\hline Toponimia & $\begin{array}{l}\text { Acaxochitlán se deriva de acatl, caña, xochitl, flor, y tlan, lugar, por tanto } \\
\text { significa "Lugar donde abunda la flor de carrizo". }\end{array}$ \\
\hline Reseña histórica & $\begin{array}{l}\text { La fundación del municipio se atribuye a los espańoles, aunque se } \\
\text { encontraba habitado ya por grupos indígenas otomíes y tepehuas, } \\
\text { quienes todavía se localizan ahí. La constitución del municipio se da } \\
\text { el } 16 \text { de enero de } 1869 \text {, la cabecera es Acaxochitlán y se encuentra a } \\
69 \mathrm{~km} \text { de la capital de estado; la lengua nativa que todavía se habla es } \\
\text { la náhuatl. }\end{array}$ \\
\hline
\end{tabular}

Localización Se encuentra en la zona del Altiplano, sobre las tierras semiplanas que conforman las primeras estribaciones de la Sierra Madre Oriental, al centro de la República Mexicana; se ubica en zonas silvestres de gran belleza natural, propiciadas por la cercanía de las presas del Tejocotal y Omiltemetl.

Ubicación Se localiza entre las coordenadas: $98^{\circ} 19^{\prime}$ a $98^{\circ} 06^{\prime}$ longitud oeste y geográfica $\quad 20^{\circ} 04^{\prime}$ a $20^{\circ} 15^{\prime}$ latitud norte. Tiene una altitud promedio de 2,240 metros sobre el nivel del mar, con altitudes registradas de 2,600 msnm. Se ubica en la parte este del estado de Hidalgo, colinda al Norte, al Este y al Sur con el estado de Puebla, y también al Sur con el municipio de Cuautepec de Hinojosa; al Oeste con los municipios de Tulancingo de Bravo y Metepec.

Clima Cuenta con clima templado húmedo con lluvias en todas las épocas del año. Presenta nublados que provocan la llamada temporada invernal que se da en forma de llovizna y neblina, bajando la temperatura a $8.3^{\circ} \mathrm{C}$; los periodos de lluvias torrenciales se dan entre mayo y octubre, alcanzando en esta temporada temperaturas de $21.2^{\circ} \mathrm{C}$.

Flora Tiene una vegetación compuesta principalmente por eucalipto, pino, encino, ocote manzanilla, encino negro, uña de gato, oyamel y cedro rojo. Además de especies no maderables como hongos, palma camedor y musgo, también se encuentran árboles de manzana, durazno, capulín, pera y una gran variedad de plantas medicinales usadas en remedios caseros.

Fauna Los animales que habitan esta zona son predominantemente de fauna boscosa, como conejos, liebres, zorrillos, tlacuaches, armadillos, ardillas, comadrejas y codornices, además de la gran variedad de reptiles, aves cantoras y arácnidos, por mencionar algunos.

Comunidades Cuenta con 36 comunidades, en su mayoría son rurales y barrios. 
Cuadro 1 (continuación)

\begin{tabular}{ll}
\hline Población & $\begin{array}{l}\text { En el año } 2005 \text { la población del municipio era de 36,978 habitantes, } \\
\text { de los cuales 17,933 son hombres y 19,045 mujeres, en relación con } \\
\text { el estado de Hidalgo representa } 0.38 \text { por ciento. }\end{array}$ \\
\hline Celebraciones & $\begin{array}{l}\text { Prácticamente todo el año tiene celebraciones, las principales son la } \\
\text { Feria Regional, la Feria de la Manzana, Semana Santa, Día de Todos } \\
\text { los Santos y Año Nuevo. }\end{array}$
\end{tabular}

Fuente: Elaboración propia con base en INEGI (2005a), Enciclopedia de los municipios de México (2002) e información proporcionada por el municipio.

\subsection{Atractivos turísticos}

La región ofrece una gran belleza natural, donde el agua es un elemento recurrente; famosa por sus presas, cuenta además con siete ríos y dos cascadas, a las cuales se puede llegar a través de un corto trayecto durante el que se puede apreciar la naturaleza. De sus atractivos, los de mayor afluencia turística actualmente son: en primer lugar, la presa del Tejocotal; en segundo, la presa de Santa Ana Tzacuala; seguido de la presa de Omiltemetl y las cascadas de San Francisco, Chimalapa y Chiveria. Tal afluencia hidrológica permite la cría, pesca y degustación de trucha arcoiris, actividad que se ha convertido en uno de sus principales atractivos.

Asimismo, las características orográficas de la zona la hacen ideal para el campismo, senderismo e instalación de cabañas, para quienes buscan un contacto más directo con la naturaleza.

Otro atractivo de la zona es el turismo gastronómico, que es el más activo, donde $80 \%$ de los turistas acude al municipio atraído por esta actividad. Destacan los restaurantes cuya especialidad es la trucha, la cual se puede encontrar en una gran diversidad de platillos. Otra variedad es la de los antojitos típicos de la región, mismos que se ofrecen en un gran número de establecimientos.

En la región se encuentran muy arraigados los usos y costumbres entre sus pobladores, lo que hace que cada comunidad cultural y socialmente sea única, lo que las distingue también por su idiosincrasia y actividad económica. Por ello es justificable la alternativa de incrementar la cultura como componente imprescindible de la oferta turística, con el objeto de diversificarla, incrementar su calidad y conseguir un valor agregado (Ávila, 2007).

Los principales atractivos donde se puede dar este tipo de combinaciones de turismo son: cascada de Chimalpalapa (campismo, etnoturismo, artesanías y goce de naturaleza), cascada de San Francisco (campismo, etnoturismo, artesanías y goce de naturaleza), presa el Tejocotal (pesca, lanchas, cabalgata, campismo, comida regional y truchas), presa Santa Ana 
Tzacuala (pesca, campismo, trucha, artesanías y etnoturismo), presa Omiltemetl (pesca, campismo, goce de naturaleza, paisaje y senderismo), Santa Catarina (paisaje, ríos, trucha, artesanías y etnoturismo), Zacacuautla (trucha, bosques y se puede apreciar la presa de Santa Ana Tzacuala), las Vueltas Acaxochitlán (bosque de pino y coníferas, flora, fauna, ciclismo y senderismo), cabecera municipal (iglesia, capilla, casas antiguas, reloj, parque Atzompa, el mirador, fabrica de vinos, refrescos de la región, tianguis dominical, comida típica y artesanías), hacienda Yemila (huertas de manzana, ciruela y durazno) y Yemila y Cuaunepantla (huertas de plantas frutales y de ornato).

\subsection{Infraestructura}

Se identificaron en el siguiente orden los principales establecimientos que sustentan la actividad turística del municipio: hospedaje, alimentos, bebidas y artesanías, y gastronomía.

a) Hospedaje. En del municipio se ofertan 65 habitaciones en hoteles, 69 cabańas y un campamento.

b) Alimentos, bebidas y artesanías. En la región se comercializan bebidas elaboradas en algunas de las comunidades (refrescos, licores y vinos). De igual forma, se encuentra una gran cantidad de vendedores ofreciendo artesanías, dulces y conservas tradicionales. La venta de estos productos se realiza en comercios establecidos y de manera informal.

\section{Cuadro 2}

Comercios establecidos y no establecidos del municipio

\begin{tabular}{|c|c|c|c|}
\hline \multicolumn{2}{|l|}{ Establecidos } & \multicolumn{2}{|l|}{ No establecidos } \\
\hline Giro & Número & Giro & Número \\
\hline Gastronomía & 22 & $\begin{array}{l}\text { Gastronomía (comida y barbacoa) } \\
\text { tianguis dominical }\end{array}$ & 32 \\
\hline Artesanías & 15 & $\begin{array}{l}\text { Artesanías (bordados: blusas, vestidos, } \\
\text { pulseras, servilletas, cobijas de lana, } \\
\text { cobijas, tianguis dominical) }\end{array}$ & 15 \\
\hline $\begin{array}{l}\text { Vinos, licores y } \\
\text { refrescos del la región }\end{array}$ & 13 & $\begin{array}{l}\text { Vinos, licores y refrescos de la región } \\
\text { tianguis dominical }\end{array}$ & 20 \\
\hline $\begin{array}{l}\text { Conservas y dulces } \\
\text { tradicionales }\end{array}$ & 5 & $\begin{array}{l}\text { Conservas y dulces tradicionales } \\
\text { tianguis dominical }\end{array}$ & 8 \\
\hline
\end{tabular}

Fuente: Elaboración propia con base en información recopilada de la región e información proporcionada por áreas de turismo del municipio de Acaxochitlán. 
Gran parte del turismo que se presenta es captado por la actividad gastronómica de la región, ya que ésta es una de las más importantes y representativas. Los restaurantes más importantes son 12, con capacidad de atención de comensales de 1,325, donde destacan las siguientes especialidades culinarias: mole de guajolote, vino de la casa, trucha en hierba santa, barbacoa, chorizo y rellena, sopa de hongo, chuleta en salsa mora, carnitas, arrachera norteña, cecina, costilla, platillo huasteco, mole poblano, conejo a la diabla y mojo de ajo, consomé de patita de pollo, pastel de nata, pecho de ternera, cabrito, osobuco, carnero, cabrito, enchiladas suizas, mixiote de carnero, barbacoa de carnero, chamorro, mixiote de hongo, filete de res, ternera, huitlacoche, pecho de carnero y tortillas al comal. Aunque en la región es común la venta de bebidas como vinos, licores y refrescos elaborados, sólo se identifica un bar.

c) Turismo de salud. Visitantes de la región y externos buscan la medicina alternativa desarrollada con la flora terapéutica, la cual en algunos casos está sustentada en estudios científicos y con la aceptación y reconocimiento de los servicios de salud del estado. En este rubro se detectó que existen 16 consultorios distribuidos en 10 comunidades que geográficamente posibilitan la creación de un corredor.

\subsection{Actores}

La Dirección de Turismo del municipio, de reciente creación, se ha convertido en el organismo rector para detonar el turismo. Al respecto destacan los esfuerzos que se han realizado en materia de concientización, planeación, organización, difusión y gestión. Algunos de los establecimientos comerciales del municipio forman parte de organismos como la Asociación de Hoteles y Moteles del Estado de Hidalgo, Cámaras de Comercio, Asociaciones de Transportistas, Asociación de Agencias de Viajes, por mencionar algunas.

La población juega un papel importante en el desarrollo de este tipo de turismo, debido a que contribuye como un elemento y actor del entorno sociocultural, con lo que su intervención en la toma de decisiones tiene efecto en el alcance de los objetivos esperados.

\subsection{Instituciones de apoyo}

Abarca al conjunto de instituciones de ámbito estatal y federal que juegan un papel en la eficiencia individual y colectiva del trade turístico, las cuales se agrupan en las siguientes categorías. 
a) Instituciones responsables de políticas de turismo: Secretaría de Turismo Federal (Sectur) y Secretaría de Turismo del Gobierno del Estado de Hidalgo.

b) Instituciones responsables de políticas o acciones con impacto en el medio ambiente: Secretaría de Medio Ambiente y Recursos Naturales (Semarnat), Comisión Nacional de Áreas Nacionales Protegidas, Comisión Nacional del Agua (Conagua), Comisión Nacional Forestal (Conafor), Procuraduría Federal de Protección al Ambiente (Profepa), Secretaría de Agricultura, Ganadería, Desarrollo Rural, Pesca y Alimentación (Sagarpa), Comisión Federal de Electricidad, que si bien no tiene funciones de impacto ambiental, sí tiene injerencia en las actividades turísticas de la zona, pues algunos de los atractivos se encuentran en zonas bajo el resguardo de esta institución.

c) Instituciones que dan soporte a las empresas: Secretaría de Economía y Secretaría de Desarrollo Social (Sedesol).

d) Instituciones ligadas a la producción o difusión del conocimiento y la tecnología: CECYTEH plantel Acaxochitlán y Universidad Autónoma del Estado de Hidalgo.

\subsection{Identificación de la potencialidad turística}

La identificación y valoración de los atractivos turísticos es una de las tareas esenciales en el proceso de planificación, que consiste en la elaboración de un listado de recursos y lugares con posibilidades de explotación turística, donde es fundamental precisar el uso de recursos turísticos y la distribución de flujos, bajo la premisa de la defensa del medio ambiente y la conservación de los valores socioculturales, debido a que estos elementos constituyen la esencia de la actividad (Poggi et al., 2006). A esto se suma una serie de intervenciones de puesta en valor hasta transformarlos en un recurso accesible para la demanda turística (Álvarez, 2000).

Para medir el potencial turístico de la región, se tomó como referencia una serie de indicadores propuestos por Sandoval (2006) en cuanto a características naturales, culturales y sociales, con una perspectiva ambiental sustentada en el enfoque holístico, el cual considera al ambiente como un sistema complejo, donde la totalidad está constituida por la naturaleza y la sociedad, es decir, incluye hechos, fenómenos naturales y socioculturales, con dinámicas propias, pero indisolublemente ligadas en mayor o menor intensidad (Serrano, 2008).

Los indicadores de potencialidad turística presentados en el cuadro 3 se definieron a través de consulta a expertos y se tomó como base: la técnica de tablas de decisión (Turner, 2002), el estudio sobre la validez en el proceso de interpretaciones e inferencias realizadas a partir de las 


\section{Cuadro 3}

\section{Rangos para evaluar los indicadores de potencialidad turística}

\begin{tabular}{|c|c|c|c|}
\hline \multirow{2}{*}{ Indicadores } & \multicolumn{3}{|c|}{$(+) \leftarrow$ Rango de potencialidad $\rightarrow(-)$} \\
\hline & 3 & 2 & 1 \\
\hline $\begin{array}{l}\text { Cercanía del área con } \\
\text { centros urbanos } \\
\text { importantes }\end{array}$ & Cerca & $\begin{array}{l}\text { Relativamente } \\
\text { cerca }\end{array}$ & Lejos \\
\hline $\begin{array}{l}\text { Características del } \\
\text { trayecto hacia el área }\end{array}$ & Cómodo & Fácil & Peligroso \\
\hline $\begin{array}{l}\text { Posibilidad de desarrollo } \\
\text { de actividades de turismo } \\
\text { de naturaleza }\end{array}$ & $\begin{array}{l}\text { Únicas por su } \\
\text { naturaleza }\end{array}$ & $\begin{array}{l}\text { Como las de muy } \\
\text { pocas zonas en el } \\
\text { país }\end{array}$ & $\begin{array}{l}\text { Como las de } \\
\text { muchas otras } \\
\text { zonas de la } \\
\text { región }\end{array}$ \\
\hline $\begin{array}{l}\text { La zona ofrece la } \\
\text { posibilidad de desarrollar } \\
\text { atractivos desde el punto } \\
\text { de vista faunístico }\end{array}$ & $\begin{array}{l}\text { Varias } \\
\text { actividades, } \\
\text { especies únicas }\end{array}$ & $\begin{array}{l}\text { Algunas } \\
\text { actividades. Otro } \\
\text { tipo de fauna }\end{array}$ & $\begin{array}{l}\text { Pocas actividades. } \\
\text { Fauna } \\
\text { representativa }\end{array}$ \\
\hline $\begin{array}{l}\text { La observación de la } \\
\text { fauna es... }\end{array}$ & Garantizada & Frecuente & $\begin{array}{l}\text { Depende de la } \\
\text { época }\end{array}$ \\
\hline La zona ofrece... & $\begin{array}{l}\text { Varias } \\
\text { características } \\
\text { de interés }\end{array}$ & $\begin{array}{l}\text { Más de una } \\
\text { característica de } \\
\text { interés }\end{array}$ & $\begin{array}{l}\text { Una sola } \\
\text { característica de } \\
\text { interés }\end{array}$ \\
\hline La zona ofrece... & $\begin{array}{l}\text { Gran interés } \\
\text { cultural }\end{array}$ & $\begin{array}{l}\text { Algunos lugares } \\
\text { de interés cultural }\end{array}$ & $\begin{array}{l}\text { Pocos lugares de } \\
\text { interés cultural }\end{array}$ \\
\hline $\begin{array}{l}\text { Las características de la } \\
\text { zona son... }\end{array}$ & Únicas & Algo diferentes & $\begin{array}{l}\text { Similares a } \\
\text { otras zonas }\end{array}$ \\
\hline $\begin{array}{l}\text { Los alrededores de la zona } \\
\text { son... }\end{array}$ & $\begin{array}{l}\text { De gran belleza } \\
\text { paisajística }\end{array}$ & $\begin{array}{l}\text { Un verdadero } \\
\text { atractivo }\end{array}$ & De poco interés \\
\hline $\begin{array}{l}\text { La cercanía de la zona a } \\
\text { otros sitios de interés } \\
\text { turístico le confiere... }\end{array}$ & $\begin{array}{l}\text { Gran potencial } \\
\text { para integrarla a } \\
\text { un circuito } \\
\text { turístico }\end{array}$ & $\begin{array}{l}\text { Potencial } \\
\text { moderado }\end{array}$ & Poco potencial \\
\hline
\end{tabular}

Fuente: Elaboración propia con base en Turner (2002), Messick (1989) y Chávez (2007).

puntuaciones que proporciona una prueba (Messick, 1989) y la metodología de Chávez (2007), a partir de lo cual se asignaron valores desde 1 , para los indicadores que presentan menor potencialidad, hasta 3 para los de mayor grado de potencialidad.

Al evaluar con el cuadro 3 los atractivos identificados en la región, se obtuvieron los resultados mostrados en el cuadro 4, donde se tienen siete aspectos con alto potencial turístico, tres con medio y ninguno con bajo potencial, lo que indica que es una región que tiene una vocación turística que puede desarrollarse con el concepto de naturaleza sustentable. 


\section{Cuadro 4 \\ Evaluación del potencial turístico de la zona}

\begin{tabular}{llll}
\hline \multicolumn{1}{c}{ Indicadores de potencialidad } & 3 & 2 & 1 \\
\hline Cercanía del área con centros urbanos importantes & $\mathrm{x}$ & \\
$\begin{array}{l}\text { Características del trayecto hacia el área } \\
\begin{array}{l}\text { Posibilidad de desarrollo de actividades de turismo de } \\
\text { naturaleza }\end{array}\end{array}$ & $\mathrm{x}$ & \\
$\begin{array}{l}\text { Presencia de atractivos desde el punto de vista faunístico } \\
\text { Características de observación de la fauna }\end{array}$ & $\mathrm{x}$ \\
$\begin{array}{l}\text { Características de interés ofrecidas por la zona } \\
\text { Interés de la zona desde el punto de vista cultural }\end{array}$ & $\mathrm{x}$ \\
$\begin{array}{l}\text { Características intrínsecas de la zona } \\
\text { Potencialidad escénica de los alrededores de la zona }\end{array}$ & $\mathrm{x}$ \\
$\begin{array}{l}\text { Potencialidad para integrar a la zona a otros sitios de interés } \\
\text { turístico }\end{array}$ & $\mathrm{x}$ & \\
\hline
\end{tabular}

Fuente: Elaboración propia.

\section{Análisis del diagnóstico por nivel}

Los principales desafíos observados en este estudio tienen una visión subyacente de actividades turísticas de naturaleza sustentable, abordadas sobre la base conceptual planteada en el modelo de la figura III. A continuación se presenta la propuesta por niveles.

\subsection{Nivel micro}

Corresponde a los atractivos turísticos y al trade (cadena de negocios relacionada con la explotación y logística del turismo), donde se analizó una serie de indicadores para medir la potencialidad turística de la zona, y se determinó que representan una opción viable para detonar el turismo a través de los atractivos naturales, turismo gastronómico, cultural y de salud, al considerar que la articulación territorial del turismo presenta conexiones con el resto de las actividades económicas, y no se limita a los procesos que transforman entornos y ambientes naturales, sino además se crean productos turísticos para satisfacer las demandas de los visitantes (Pardellas y Padín, 2004). El área presenta una serie de características que la torna interesante para la formación de un cluster turístico de naturaleza sustentable, como la cantidad y diversidad de lugares naturales con- 
centrados en un radio de $30 \mathrm{~km}$, entre las que destacan: ríos, cascadas, presas, zonas para senderismo y escalada, fauna terrestre y flora.

Entre los retos encontrados se tiene lo siguiente:

- Atractivos naturales sin explotar.

- Explotación inadecuada de medios acuáticos.

- Explotación forestal desmedida.

- Mano de obra local poco calificada.

- Bajo nivel de capitalización.

- Reducida capacidad empresarial.

Para enfrentar dichos retos se proponen las siguientes recomendaciones:

- Fomentar la organización de los habitantes de las comunidades del municipio a fin de impulsar proyectos productivos o proyectos de naturaleza turística.

- Impulsar programas de capacitación a artesanos y prestadores de servicios.

- Elaborar una cartera de proyectos.

- Buscar financiamiento para los proyectos que ya se encuentran en proceso de gestión.

- Promover la capacitación empresarial y la calificación de la mano de obra local, para mejorar la calidad de los servicios turísticos.

- Implementar mecanismos que ayuden a identificar y mejorar las cadenas productivas de las actividades de los diferentes segmentos del trade.

- Diseñar y utilizar un sistema de acreditación, para los servicios del trade.

- Fomentar actividades del sector primario y de artesanía para comercialización en el trade.

\subsection{Nivel meta}

Se refiere al nivel de organización que repercute en el nivel micro, es decir, la capacidad que tienen los integrantes del trade para seguir un objetivo en común. La competitividad de este nivel cobra mayor importancia en el caso de los clusters turísticos, en la medida en que se traslada al desarrollo sustentable del sector. La actuación coordinada de los agentes que intervienen en el trade estará en función de objetivos comunes, lo cual exige un elevado grado de cohesión social y política.

La primera dificultad para la definición de objetivos y estrategias se encontró en el reducido número de empresarios que poseen una visión estratégica de mediano y largo plazos, ya que el éxito del producto turístico depende de la calidad de un conjunto de componentes mucho más amplio que el 
compuesto por los atractivos, especialmente la infraestructura turística y la preservación del medio ambiente. Otro problema importante se relaciona con la ausencia de una cultura asociativa entre la gran mayoría de los prestadores de servicios.

Para poder valorar este nivel se aplicó una dinámica de planeación participativa, donde se reunió a los principales actores para identificar tanto su percepción como su visión, a partir de la cual sobresalieron las siguientes características, desafíos y recomendaciones.

\section{Características}

- Interés de los actores, quienes conscientes del gran potencial turístico de la región, han comenzado a planear acciones que contribuyan al desarrollo de las actividades turísticas.

- Un creciente interés por el desarrollo turístico por parte de los líderes empresariales locales, a la par de un mayor conocimiento de la importancia de la preservación del medio ambiente.

Desafíos

- Poca capacidad estratégica de los agentes involucrados de los sectores público y privado, que limitan sus acciones a un corto plazo.

- Incipiente capacidad asociativa y de confianza entre los agentes.

- Falta de conciencia de la población local de su rol en la construcción de una región turística.

- Falta de percepción, por parte de los agentes, en el sentido de que la calidad del producto turístico depende de la calidad ambiental, infraestructura urbana, medios de acceso y manifestaciones de la cultura local, y no sólo del trade turístico.

Recomendaciones

- Reducir antagonismos entre los actores.

- Elaborar un plan rector de turismo para la región.

- Definir proyectos comunes y alineados que indiquen los rumbos del turismo de naturaleza sustentable de mediano y largo plazos.

- Elaborar las directrices para la comunidad, donde se involucre a las asociaciones representativas de los segmentos del trade.

- Crear un consejo municipal de turismo.

- Concientizar a la población local en cuanto a la responsabilidad de cada segmento de la sociedad en este proyecto. 
- Identificar indicadores del turismo actual, con la finalidad de tener parámetros de comparación, trazar estrategias y proporcionar un equilibrio en su desarrollo.

- Responsabilizar a la Dirección de Turismo para asumir su atribución como instancia gestora y rectora de las directrices de mediano y largo plazos en el desarrollo del turismo.

\subsection{Nivel macro}

Se identificaron instituciones a nivel supralocal, las cuales se agrupan en las siguientes instituciones: responsables de políticas de turismo; responsables de políticas relacionadas con el medio ambiente; las que dan soporte a las empresas; organizaciones no gubernamentales; las ligadas a la producción, difusión del conocimiento y tecnología, y agencias turísticas. El conjunto de estas entidades integran el entorno responsable para la generación de los factores de competitividad. A partir del análisis desarrollado en este nivel se identificaron los siguientes desafíos, de los cuales emanaron las respectivas recomendaciones.

Desafíos

- Necesidad de coordinar a las instituciones para actuar como grupo.

- Falta de dirección en las políticas específicas para este rubro.

- Carencia de un plan de desarrollo y ordenamiento ecológico.

- Baja de credibilidad en las instituciones agrupadas en este nivel.

\section{Recomendaciones}

- Fomentar la articulación entre los líderes del trade, dirigentes del poder público local e instituciones de apoyo.

- Fortalecer el marco regulatorio para orientar las políticas de desarrollo del sector.

- Incentivar a universidades y centros de investigación para realizar proyectos que respondan a las necesidades turísticas de la región.

- Promover estudios sobre el potencial de los atractivos naturales de la región.

- Promover el impacto de los programas de corto plazo como elementos de difusión y credibilidad de los actores implicados.

\subsection{Nivel meta}

Representa el ambiente global, donde se encuentran las condiciones económicas de las distintas regiones y entidades adyacentes, la sociedad 
como mercado objetivo, la competitividad con otras regiones del estado, Tlaxcala y Puebla, y la cultura que la sociedad manifiesta para viajar a zonas turísticas de esta índole. Con base en los análisis realizados se identificaron los siguientes desafíos con sus respectivas recomendaciones.

\section{Desafíos}

- Necesidad de conocer la vocación turística, de servicio e infraestructura de las regiones.

- Falta de coordinación y gestión con el nivel macro para difusión de los perfiles turísticos de la zona.

- Ausencia de un diagnóstico de tipo exploratorio.

- Necesidad de desarrollar indicadores del sector.

- Falta de políticas de desarrollo para la región.

\section{Recomendaciones}

- Elaborar un mapeo de regiones con potencial turístico.

- Direccionar políticas y recursos para la región.

- Difundir ante la sociedad los perfiles turísticos de la región.

\section{Identificación de proyectos}

Con base en los análisis anteriores, se elaboró una cartera de proyectos estratégicos sustentada en las características propias, vocación, perfiles y necesidades identificadas en el diagnóstico de la región, con la finalidad de desarrollar y fortalecer las diferentes vertientes del turismo, donde los proyectos propuestos tuvieron como premisa la preservación del medio ambiente. En este proceso fue fundamental la participación de los actores involucrados y expertos en diferentes disciplinas. Complementan lo anterior las siguientes consideraciones para la gestión y promoción de la cartera de proyectos:

- Tomar en cuenta los objetivos, metas y voluntades políticas, aspectos sociales, aspectos técnicos y económico-financieros (Boullón, 1990).

- Considerar los costos económicos y sociales, ya que la consecución de un proyecto de este tipo no se da en el corto plazo (Cunha y Aricó, 2001).

En el cuadro 5 se desglosan las diferentes vertientes del turismo, donde se consideró lo que se hace actualmente y aquello que muestra potencial para explotarse. 


\section{Cuadro 5}

\section{Vertientes turísticas y sus actividades}

\begin{tabular}{|c|c|c|}
\hline \multicolumn{2}{|c|}{ Vertientes del turismo } & Actividades y productos \\
\hline \multirow{4}{*}{ Turismo cultural } & Arqueología & $\begin{array}{l}\text { - Pinturas rupestres } \\
\text { - Pirámides }\end{array}$ \\
\hline & Artesanía & $\begin{array}{l}\text { - Muebles } \\
\text { - Tejidos, hilados y bordados } \\
\text { - Bisutería regional }\end{array}$ \\
\hline & Danza y música & - Danzas autóctonas \\
\hline & Religioso & - Celebraciones patronales \\
\hline \multirow[b]{2}{*}{ Turismo gastronómico } & Bebidas & $\begin{array}{l}\text { - Vinos } \\
\text { - Licores } \\
\text { - Refrescos }\end{array}$ \\
\hline & Comida típica & $\begin{array}{l}\text { - Comida y antojitos regionales } \\
\text { - Cocina autóctona } \\
\text { - Trucha } \\
\text { - Dulces y conservas }\end{array}$ \\
\hline Turismo natural & $\begin{array}{l}\text { Deportivo, } \\
\text { recreativo y de } \\
\text { aventura }\end{array}$ & $\begin{array}{l}\text { - Caminatas de observación } \\
\text { - Paseos a caballo } \\
\text { - Ciclismo de montańa } \\
\text { - Tirolesa } \\
\text { - Campismo } \\
\text { - Senderismo } \\
\text { - Pesca } \\
\text { - Paseos en bote }\end{array}$ \\
\hline \multirow[t]{2}{*}{ Turismo de salud } & $\begin{array}{l}\text { Medicina } \\
\text { alternativa y } \\
\text { rituales esotéricos }\end{array}$ & $\begin{array}{l}\text { - Hueseros y curanderos } \\
\text { - Brujos } \\
\text { - Baños de temascal }\end{array}$ \\
\hline & Botánica & - Plantas medicinales \\
\hline
\end{tabular}

Fuente: Elaboración propia. 


\section{Cuadro 6}

\section{Cartera de proyectos}

\begin{tabular}{|c|c|}
\hline Proyectos & Caracteristicas \\
\hline $\begin{array}{l}\text { 1. Creación del } \\
\text { consejo municipal } \\
\text { de turismo }\end{array}$ & $\begin{array}{l}\text { Organo que regule el turismo en la región y establezca las } \\
\text { directrices de la actividad turística. Se debe legislar la } \\
\text { propuesta en el ámbito municipal para la formación del } \\
\text { consejo, el cual deberá tener representación de todos los } \\
\text { actores involucrados en el cluster turístico }\end{array}$ \\
\hline $\begin{array}{l}\text { 2. Creación de la } \\
\text { casa de cultura }\end{array}$ & $\begin{array}{l}\text { Permitirá el rescate, fomento y difusión de las distintas } \\
\text { manifestaciones artísticas, así como del legado cultural de } \\
\text { la región }\end{array}$ \\
\hline $\begin{array}{l}\text { 3. Creación del } \\
\text { museo municipal }\end{array}$ & $\begin{array}{l}\text { Permitirá tomar las medidas necesarias para preservar y } \\
\text { salvaguardar la integridad del patrimonio histórico y } \\
\text { cultural. Además se podrán planificar, programar, organizar } \\
\text { y realizar exhibiciones culturales, artísticas y arqueológicas } \\
\text { que conlleven a rescatar los valores e identidad }\end{array}$ \\
\hline $\begin{array}{l}\text { 4. Desarrollo de un } \\
\text { parián } \\
\text { gastronómico }\end{array}$ & $\begin{array}{l}\text { Constituye una forma de agrupar comercios, para ofrecer a } \\
\text { los visitantes la variedad de productos de la región en un } \\
\text { lugar delimitado, con una imagen innovadora y moderna, } \\
\text { sin perder el sentido de identidad característica de la zona }\end{array}$ \\
\hline $\begin{array}{l}\text { 5. Creación de un } \\
\text { zoológico de } \\
\text { unidades de } \\
\text { manejo de vida } \\
\text { silvestre }\end{array}$ & $\begin{array}{l}\text { Con la finalidad de rescatar, conservar y difundir la riqueza } \\
\text { fáunica de la región }\end{array}$ \\
\hline $\begin{array}{l}\text { 6. Potencialización } \\
\text { de actividades de } \\
\text { deportes } \\
\text { acuáticos }\end{array}$ & $\begin{array}{l}\text { Las actividades que se pueden realizar son: paseos en bote, } \\
\text { pesca, remo y kayak, las cuales no perturban el medio, } \\
\text { debido a que se cuenta con dos cascadas y tres presas, que } \\
\text { pueden albergar una serie de actividades tanto recreativas } \\
\text { como deportivas }\end{array}$ \\
\hline $\begin{array}{l}\text { 7. Creación del } \\
\text { centro } \\
\text { ecoturístico }\end{array}$ & $\begin{array}{l}\text { Orientado principalmente a turistas no especializados. En } \\
\text { este centro se podrá concentrar una serie de actividades } \\
\text { como paseos a caballo, ciclismo de montańa, tirolesa, } \\
\text { campismo, escalada y senderismo, además de los servicios } \\
\text { de alojamiento, alimentación y traslado }\end{array}$ \\
\hline $\begin{array}{l}\text { 8. Obtención del } \\
\text { reconocimiento } \\
\text { de pueblo mágico }\end{array}$ & $\begin{array}{l}\text { Donde se persiguen los objetivos sectoriales siguientes: } \\
\text { Propiciar el desarrollo sustentable, estatal y regional } \\
\text { Fomentar la oferta turística } \\
\text { Apoyar el desarrollo turístico municipal } \\
\text { Favorecer la dotación de infraestructura en apoyo al turismo }\end{array}$ \\
\hline $\begin{array}{l}\text { 9. Implementación } \\
\text { del programa de } \\
\text { reordenamiento } \\
\text { del comercio } \\
\text { semifijo y } \\
\text { ambulante }\end{array}$ & $\begin{array}{l}\text { Para ordenar y controlar el comercio semifijo y ambulante } \\
\text { en las zonas de alta concentración de visitantes y en los } \\
\text { sitios de interés turístico }\end{array}$ \\
\hline
\end{tabular}


Cuaro 6 (continuación)

\begin{tabular}{cl}
\hline \multicolumn{1}{c}{ Proyectos } & \multicolumn{1}{c}{ Características } \\
\hline $\begin{array}{c}\text { 10. Formación de } \\
\text { guías turísticos }\end{array}$ & $\begin{array}{l}\text { Representantes directos de la imagen turística del } \\
\text { municipio, lo cual demanda su profesionalización }\end{array}$ \\
\hline $\begin{array}{c}\text { 11. Creación de la } \\
\text { agencia de } \\
\text { turismo }\end{array}$ & $\begin{array}{l}\text { Dependencia operativa donde se ofrezca y distribuya } \\
\text { información acerca de todas las opciones de que dispone la } \\
\text { región en materia de turismo, así como de los servicios que } \\
\text { el visitante puede contratar }\end{array}$ \\
\hline $\begin{array}{c}\text { 12. Colocación de } \\
\text { seńalética y } \\
\text { mapas }\end{array}$ & $\begin{array}{l}\text { Para orientar e informar al turista a través de comunicación } \\
\text { visual acerca de los accesos y sitios de interés turístico }\end{array}$ \\
\hline $\begin{array}{c}\text { 13. Creación del } \\
\text { reglamento de } \\
\text { imagen urbana }\end{array}$ & $\begin{array}{l}\text { Para desarrollar y mantener una imagen paisajista, de } \\
\text { acuerdo con el estilo arquitectónico-rural de la región }\end{array}$ \\
\hline $\begin{array}{l}\text { 14. Gestión de } \\
\text { políticas y } \\
\text { recursos }\end{array}$ & $\begin{array}{l}\text { Establecimiento de alianzas con los diferentes órdenes de } \\
\text { gobierno, la iniciativa privada y el sector educativo, que } \\
\text { sustente la vocación y capacidades de la región en materia } \\
\text { de turismo de naturaleza sustentable, con la finalidad de } \\
\text { implementar las estrategias orientadas al desarrollo, donde } \\
\text { el marco regulatorio, la mercadotecnia, la gestión y los } \\
\text { recursos converjan en el cumplimiento de los objetivos }\end{array}$ \\
\end{tabular}

Fuente: Elaboración propia.

Derivado de las vertientes turísticas identificadas en el estudio y planteadas en el nivel micro del modelo reportado, en el cuadro 6 se presenta la cartera de proyectos resultantes de la investigación.

\section{Conclusiones y recomendaciones}

El modelo sistémico permitió tener un panorama de las relaciones que deben tomarse en cuenta en la región. Asimismo, contribuyó a desarrollar el diagnóstico y focalizar las estrategias de acuerdo con los niveles y vertientes turísticos planteados.

El modelo sistémico de turismo está soportado en cuatro vertientes: natural, de salud, gastronómico y cultural; así como en la cadena de valor del turismo, las cuales permiten una mejor relación y cooperación entre los diferentes niveles detectados: micro (trade), meso (actores locales), macro (actores supralocales) y meta (sistema general). Con esta base, se identificaron los diferentes elementos, sus interrelaciones y la situación general que guardan respecto al medio en el que se desenvuelven.

Se encontró que se necesita mayor integración en el sector turístico para que se puedan eliminar limitantes generadas por los actores y la sociedad, a través de la conceptualización y entendimiento del sistema como se ex- 
pone en el trabajo, para generar alternativas estructuradas y articuladas, donde se tome en cuenta la necesidad de sensibilizar a los actores acerca de los beneficios que provee el desarrollo del turismo a la región.

La actividad turística sustentable de naturaleza crea una conciencia sobre el ambiente, el patrimonio, la cultura y su valor económico, proporcionando un sentido de identidad y pertenencia, que a la vez propicia una reducción de vulnerabilidad que se da a través de la diversificación de los recursos.

El gobierno debe estar comprometido con la planeación y el diseño de estrategias para el desarrollo de un turismo holístico en alianza con la comunidad y los accionistas de la industria, que incluya expectativas reales de los beneficios sociales, culturales y ambientales que fortalezcan la región.

Se recomienda el uso de estrategias que contemplen las siguientes tareas: análisis y difusión de las cualidades y calidades del producto/servicio, mediante el estudio del perfil de cada atractivo y equipamiento e instalaciones para facilitar su operación turística; definición de la imagen a proyectar en cada lugar; además de la selección de los medios publicitarios y mensajes a utilizar.

Las perspectivas de desarrollo de las diferentes vertientes de turismo sustentable de naturaleza, así como las formas de gestión que propicien una mejor articulación entre los agentes de la cadena de valor, demandan modelos de análisis que, con un enfoque sistémico, identifiquen y dimensionen los elementos de mayor efecto que convergen en el planteamiento y estudio de una problemática, así como en la formulación de las estrategias de solución.

\section{Bibliografía}

Abreu, José (2009), "Situación actual de la RSE en el sector turístico mexicano", Daena: International Journal of Good Conscience, 4 (2), SEP, México, pp. 160-173.

Álvarez, Cristina (2000), "Modelo de desarrollo turístico de un área rural en declive", Observatorio Medioambiental, 3, Universidad Complutense, Madrid, pp. 419-435.

Ávila, Rosa (2007), Turismo cultural en México: alcance y perspectivas, Trillas, México.

Andrés, Juan y Matilde Encabo (2008), "Concepto de área natural turística” como aporte teórico para la planificación sustentable del turismo, El Periplo Sustentanble, 13, Universidad Autónoma del Estado de México, México, pp. 91-111. 
Ascanio, Alfredo (2004), "Turismo y desarrollo de la comunidad: un primer paso para rescatar la identidad cultural", Pasos. Revista de Turismo y Patrimonio Cultural, 2, Caracas, pp. 155-161.

Beni, Mario (1998), Analise estructural do turismo, senac, Sao Paulo.

Boullón, Roberto (1990), Las actividades turisticas y recreacionales: el hombre como protagonista, Trillas, México.

Boullón Roberto (2003), Ecoturismo, sistemas naturales y urbanos, Ediciones Turísticas de Mario Banchik, Buenos Aires.

Cárdenas, Fabio (2006), Proyectos turísticos, localización e inversión, Trillas, México.

Cevallos, Héctor (1998), Ecoturismo. Naturaleza y desarrollo sostenible, Diana, México.

Chávez-de la Peña, Jorge (2007), Ecoturismo TAP, metodología para un turismo ambientalmente planificado, Trillas, México.

Cobo, Francisco, Annie Hervé y María Aparicio (2009), "El sistema turístico en clave de marketing relacional: el factor relacional", Anuario Jurídico y Económico Escurialense, XLII, Real Centro Universitario Escorial-María Cristina, San Lorenzo de El Escorial, pp. 419-442.

Cooper, Chris, John Fletcher, Sthephen Wanhill y David Gilbert (1996), Turismo, principios y práctica, Diana, México.

Cunha, María y Roberto Aricó (2001), La formación de un cluster en torno al turismo de naturaleza sustentable en Bonito, Brasil, CEPAL, Santiago de Chile.

Enciclopedia de los municipios de México (2002), Estado de Hidalgo: municipio de Acaxochitlán (CD), Instituto Nacional para el Federalismo y el Desarrollo Municipal-Gobierno del Estado de Hidalgo, México.

Esser, Klaus, Wolfgang Hillebrand, Dirk Messner y Jörg Meyer-Stamer (1996), "Competitividad sistémica: nuevo desafío a las empresas y a la política", Revista de la CEPAL, 59, Santiago de Chile, pp. $39-52$. 
Fonseca, María (2009), "Punta Mita en la dinámica del desarrollo turístico regional", El Periplo Sustentable, 16, Universidad Autónoma del Estado de México, México, pp. 85-108.

Gobierno del Estado de Hidalgo (2005), Plan estatal de desarrollo 20052011, Periódico Oficial, 41, 3 de octubre, Pachuca.

Goeldner, Charles y Ritchie Brent (2002), Turismo: principios, prácticas e filosofias, Bookman, Porto Alegre.

Hall, Michael y Richard Mitchell (2002), Tourism as a force for gastronomic globalization and localization, Tourism and Gastronomy, Londres.

Hernández, Roberto, Carlos Fernández y Pilar Baptista (2006), Metodología de la investigación, McGraw-Hill, México.

INEGI (Instituto Nacional de Estadística, Geografía e Informática) (2005a), Conteo de población y vivienda 2005, INEGI, México.

INEGI (Instituto Nacional de Estadística, Geografía e Informática) (2005b), Marco geoestadístico municipal, INEGI, México.

Labandeira, Xavier, Carmelo León y María Xosé Vázquez (2007), Economía ambiental, Pearson, Madrid.

López, Diego (2006), "El modelo turístico de carácter sistémico e integrado como facilitador del desarrollo en los países centroamericanos: el caso de Nicaragua", Documents D’análisis Geográfica, 47, Universidad Autónoma de Barcelona, Barcelona, pp. 69-91.

Malhotra, Naresh (2008), Investigación de mercados, un enfoque práctico, Prentice Hall, México.

Messick, Samuel (1989), Validity, R.L. Linn, Nueva York.

Meyer-Stamer, Jörg (2008), "Systemic Competitiveness and Local Economic Development", Large Scale Systemic Change: Theories, Modelling and Practices, Duisburg, Alemania, pp. 1-23.

Miguel Velasco, Andrés Enrique, Pedro Maldonado Cruz, Julio César Torres Valdéz y Maritza Cruz Atayde (2008), "La entropía como 
indicador de las desigualdades regionales en México", Economía Sociedad y Territorio, 8, (27), El Colegio Mexiquense, Zinacantepec, pp. 693-719.

Montero, Cecilia y Constanza Parra (2001), "Casos locales: El cluster del ecoturismo en San Pedro", en Memorias del seminario internacional del ecoturismo: politicas locales para oportunidades globales, CEPAL, Santiago, pp. 93-114.

Oliveira, Glauber (2007), "Modelos teóricos aplicados al turismo", Estudios y Perspectivas en Turismo, 16, Buenos Aires, pp. 96-108.

Oliveira, Glauber (2007), "La importancia de la gastronomía en el turismo, un ejemplo de Mehalda, Portugal", Estudios y Perspectivas en Turismo, 16, Buenos Aires, pp. 261-282.

Otero, Adriana (1997), Plan de desarrollo recreativo turístico de la zona norte de la provincia de Neuquén, Copade-Universidad Nacional del Comahue, Neuquén.

Pardellas, Xulio y Carmen Padín (2004), "La planificación turística sostenible: un análisis aplicado al municipio de Caldas de Reis", Revista Galega de Economía, 13 (2), Facultad de Ciencias Económicas y Empresariales, Galicia, pp. 1-18.

Pascarella, Roberto y Joaquim Rubens (2010), "Competitividad de los destinos turísticos", Estudios y Perspectivas en Turismo, 19, Buenos Aires, pp. 1-17.

Peres, Wilson (2006), "El lento retorno de las políticas industriales en América Latina y el Caribe", Revista de la CEPAL, 88, Santiago de Chile, pp. 71-88.

Pérez, Mónica (2004), Manual del turismo sustentable, Aedos, México.

PNUD (Programa de las Naciones Unidas para el Desarrollo) (2008), Índice de desarrollo humano municipal en México 2000-2005, PNUD, México.

Poggi, Marta, Mariselma Ferreira y Doris van de Meene (2006), "Competitividad y turismo sustentable. El caso de Aguas de San Pedro 
(San Pablo, Brasil)", Estudios y Perspectivas en Turismo, 15, Buenos Aires, pp. 220-235.

Porter, Michael (1990), The Competitive Advantage of Nations, The Free Press, Nueva York.

Porter, Michael (2002), Ventaja competitiva: creación y sostenimiento de un desarrollo superior, Patria, México.

Porter, Michael (2008), "The Five Competitive Forces That Shape Strategy", Harvard Business Review, enero, Boston, pp. 78-93.

Ramírez, César (2006), Marketing turistico, Trillas, México.

Rodríguez, Salvador (2007), “Los espacios del turismo en el territorio del Plan Puebla-Panamá", Ciencias Sociales Online, Universidad de Viña del Mar, Viña del Mar, pp. 119-138.

Ruiz, Manuel, Ricardo Jiménez, Mario Márquez y George Alleyne (1994), "Salud y turismo", Revista Salud Pública en México, 36, México, pp. 61-69.

Ruiz, Octavio (2008), “Turismo: factor de desarrollo y competitividad en México", documento de trabajo núm. 46, Centro de Estudios Sociales y de Opinión Pública, México.

Salinas, Eduardo y José Osorio (2006), "Turismo y sustentabilidad: de la teoría a la práctica en Cuba”, Cuadernos de Turismo, 17, Murcia, pp. 201-221.

Saramago, Alfredo (2002), Gastronomía, patrimonio cultural In: Com os Olhos no Futuro. Reflexoes Sobre o Turismo em Portugal, ICEP, Lisboa.

Sandoval, Ewaldo (2006), Ecoturismo, operación técnica y gestión ambiental, Trillas, México.

Sectur, Cestur-uam (Secretaría de Turismo, Centro de Estudios Superiores en Turismo-Universidad Autónoma Metropolitana (2007), Elementos para evaluar el impacto económico, social y ambiental del turismo de naturaleza en México, Sectur-uAm, México. 
Sectur (Secretaría de Turismo) (2007), Integración de agrupamientos turísticos competitivos. Clusters turísticos, Sectur, México.

Sectur (Secretaría de Turismo) (2008), Agenda 21 para el turismo mexicano: un marco de acción para el desarrollo sustentable de la actividad turistica, Sectur, México.

Serrano-Barquín, Rocío (2008), "Hacia un modelo teórico-metodológico para el análisis del desarrollo, la sostenibilidad y el turismo", Economía, Sociedad y Territorio, 8 (26), El Colegio Mexiquese, Zinacantepec, pp. 313-356.

Silva, Jorge (2005), "Turismo, crescimiento e desenvolvimento: uma análise urbano-regional baseade em cluster", Urban Public Economics Review, 3, Universidad de Santiago de Compostela, Santiago de Compostela, pp. 102-105.

Tarlombani, Marcos ((2005), “Turismo y sustentabilidad, entre el discurso y la acción”, Estudios y Perspectivas en Turismo, 14, Centro de Investigaciones y Estudios Turísticos, Buenos Aires, pp. 222-242.

Turner, Suzanne (2002), Tools for success: A Manager's Guide, McGrawHill, Londres.

Urquidi, Víctor (2002), Los desafios del desarrollo sustentable en la región latinoamericana, El Colegio de México, México.

Van Broeck, Anne (2005), “Introducción”, en Frausto Martínez (comp.), Desarrollo sustentable: turismo, costas y educación, Universidad de Quintana Roo, Cozumel, pp. 15-28.

Varisco, Cristina (2004), "El cluster turístico de Miramar", Aportes y Transferencias, 8 (2), Universidad Nacional de Mar del Plata, Mar del Plata, pp. 61-88.

Vera, Fernando (1997), Análisis territorial del turismo. Una nueva geografía del turismo, Ariel, Barcelona.

Vergara, Patricio y Myrtis Arrais (2005), "Planificación turística en tiempos de incertidumbre", Ciencias Sociales Online, II, Universidad de Viña del Mar, Viña del Mar, pp. 65-83. 
Recibido: 12 de agosto de 2010. Reenviado: 27 de octubre de 2010. Aceptado: 7 de marzo de 2011.

Oscar Montańo-Arango. Es doctor en ingeniería (sistemas de planeación), área académica de ingeniería y arquitectura del Instituto de Ciencias Básicas e Ingeniería, Universidad Autónoma del Estado de Hidalgo. Líneas de investigación: planeación, sistemas suaves y procesos. Entre sus publicaciones sobresalen: en coautoría, "Modelo que identifica la madurez de los procesos. Caso: pequeña empresa manufacturera”, DYNA Engineering and Industry, 85 (5), DYNA, Bilbao, pp. 392-400 (2010); en coautoría, "Innovación en las pyMEs: desarrollo de un modelo, para el estado de Hidalgo", en José Sánchez (comp.), La competitividad como estrategia en época de crisis, Universidad de Guadalajara, Guadalajara, pp. 211-228 (2010); en coautoría, "Plan estratégico para detonar el desarrollo económico social del municipio de Acaxochitlán”, Innova, 2, Cocytech, Pachuca, pp. 16-19 (2009); en coautoría, "Generación de conocimiento para la competitividad a través de los sistemas de innovación tecnológica: jerarquización de diversas organizaciones a través de los métodos multicriterio de ayuda para la toma de decisiones", Mercados y Negocios, 18, Universidad de Guadalajara, Guadalajara, pp. 80-92 (2008).

José Ramón Corona-Armenta. Es doctor en ingeniería (sistemas industriales), área académica de ingeniería y arquitectura del Instituto de Ciencias Básicas e Ingeniería, Universidad Autónoma del Estado de Hidalgo. Líneas de investigación: planeación, sistemas organizacionales y procesos. Entre sus publicaciones sobresalen: en coautoría, "Modelo que identifica la madurez de los procesos. Caso: pequeña empresa manufacturera”, DYNA Engineering and Industry, 85 (5), DYNA, Bilbao, pp. 392400 (2010); en coautoría, "Innovación en las pYMEs: desarrollo de un modelo, para el estado de Hidalgo", en José Sánchez (comp.), La competitividad como estrategia en época de crisis, Universidad de Guadalajara, Guadalajara, pp. 211-228 (2010); en coautoría, "Plan estratégico para detonar el desarrollo económico social del municipio de Acaxochitlán", Innova, 2, Cocytech, Pachuca, pp. 16-19, (2009); en coautoría, "Generación de conocimiento para la competitividad a través de los sistemas de innovación tecnológica: jerarquización de diversas organizaciones a través de los métodos multicriterio de ayuda para la toma de decisiones", Mercados y Negocios, 18, Universidad de Guadalajara, Guadalajara, pp. 80-92 (2008). 
Jaime Garnica-González. Es maestro en ingeniería (planeación), área académica de ingeniería y arquitectura del Instituto de Ciencias Básicas e Ingeniería, Universidad Autónoma del Estado de Hidalgo. Líneas de investigación: análisis, diseño y optimización de sistemas sociotécnicos. Actualmente estudia el doctorado en planeación estratégica. Entre sus publicaciones sobresalen: en coautoría, "Una visión de competitividad sistémica para el planteamiento de proyectos turísticos de naturaleza sustentable. Caso del municipio Acaxochitlán, Hidalgo, México", Memorias del XIV Congreso Internacional de Investigación en Ciencias Administrativas, Acacia, Egade-Tecnológico de Monterrey, Monterrey, documento C11P6C 1-30 (2010); en coautoría, "Plan estratégico para el manejo de materiales peligrosos. Estudio de caso: Unidad Central de Laboratorios", Memorias del Tercer Congreso Anual de la Red Internacional de Investigadores en Competitividad, Universidad de Guadalajara, Puerto Vallarta, pp. 1674-1693 (2009); en coautoría, "El modelo educativo de la UAEH como factor de competitividad, una perspectiva de sus dimensiones a través del enfoque de sistemas", Memorias del XII Congreso Internacional de Investigación en Ciencias Administrativas, Acacia, Cetys-Universidad de Baja California, Tijuana, documento M09P24 1-22 (2008).

Heriberto Niccolas-Morales. Es maestro en ingeniería (planeación), área académica de ingeniería y arquitectura del Instituto de Ciencias Básicas e Ingeniería, Universidad Autónoma del Estado de Hidalgo. Líneas de investigación: análisis, diseño y optimización de sistemas sociotécnicos. Es director de Estudios Estratégicos y Desarrollo Institucional de la UAEH (2006-2010). Entre sus publicaciones sobresalen: en coautoría, "Una visión de competitividad sistémica para el planteamiento de proyectos turísticos de naturaleza sustentable. Caso del municipio Acaxochitlán, Hidalgo, México", Memorias del XIV Congreso Internacional de Investigación en Ciencias Administrativas, Acacia, Egade-Tecnológico de Monterrey, Monterrey documento C11P6C 1-30 (2010); en coautoría, "Plan estratégico para el manejo de materiales peligrosos. Estudio de caso: Unidad Central de Laboratorios", Memorias del Tercer Congreso Anual de la Red Internacional de Investigadores en Competitividad, Universidad de Guadalajara, Puerto Vallarta, pp. 1674-1693 (2009); en coautoría, "El modelo educativo de la UAEH como factor de competitividad, una perspectiva de sus dimensiones a través del enfoque de sistemas", Memorias del XII Congreso Internacional de Investigación en Ciencias Administrativas, Acacia, Cetys-Universidad de Baja California, Tijuana, documento M09P24 1-22(2008). 
Pablo Martínez-Castelán. Es maestro en ciencias en ingeniería industrial (planeación) por la Universidad Autónoma del Estado de Hidalgo. Líneas de investigación: análisis, diseño y optimización de sistemas sociotécnicos. Entre sus publicaciones sobresalen: en coautoría, "Una visión de competitividad sistémica para el planteamiento de proyectos turísticos de naturaleza sustentable. Caso del municipio Acaxochitlán, Hidalgo, México", Memorias del XIV Congreso Internacional de Investigación en Ciencias Administrativas, Acacia, Egade-Tecnológico de Monterrey, Monterrey documento C11P6C 1-30 (2010); en coautoría, "Modelo sistémico para el fomento del desarrollo industrial en la ciudad de Pachuca, Hidalgo, México".

Antonio Oswaldo Ortega-Reyes. Es doctor en ciencias administrativas por la Escuela Superior de Comercio y Administración del Instituto Politécnico Nacional en donde obtuvo Mención Honorífica. Actualmente labora en el área académica de ingeniería industrial, Instituto de Ciencias Básicas e Ingeniería de la Universidad Autónoma del Estado de Hidalgo. Líneas de investigación: cultura organizacional, identidad corporativa, inteligencia directiva y enfermedades del ambiente laboral. Entre sus publicaciones sobresalen: en coautoría, "El capital intelectual en las fases de innovación tecnológica”, Revista Oikos, 13 (27), pp. 67-86, Universidad Católica Silvia Henríquez, Santiago de Chile (2009); "La creatividad como factor técnico inicial en el proceso de innovación tecnológica”, Revista Internacional La Nueva Gestión Organizacional, 4 (7), Universidad Autónoma de Tlaxcala, México, pp. 149-161 (2008). 